\title{
Perancangan Aplikasi Layanan Tugas Akhir Mahasiswa Berbasis Knowledge Management
} \author{
Agil Santosa 6 \\ 1, 2, 3,4 Ilmu Komputer, Institut Pertanian Bogor \\ ${ }^{5,6} \mathrm{Ilmu}$ Komputer, Universitas Singaperbangsa karawang \\ ${ }^{1}$ haeruljajam@apps.ipb.ac.id \\ 2abdulmufti@apps.ipb.ac.id \\ 3 irmanhermadi@apps.ipb.ac.id \\ ${ }^{4}$ imamsuroso@gmail.com \\ 5 christmemory@gmail.com \\ ${ }^{6}$ agilsantosa64@gmail.com
}

Jajam Haerul Jaman ${ }^{1}$; Abdul Mufti ${ }^{2}$;rman Hermadi ${ }^{3}$; Arif Imam Suroso ${ }^{4}$; Christmemory Sitorus ${ }^{5}$;

\begin{abstract}
Student final assignment services online via smartphone (android) at Indraprasta University PGRI (Unindra) do not yet exist, while the number of graduates each year is quite large so it is rather troublesome for administrative staff in serving students who will prepare theses. The purpose of this study is to facilitate students in taking care of the administration of the final project. The research method used is Research and Development $(R \& D)$. The expected result in this research is that students who will prepare their final project more easily in the process of the final project, namely by mobile phone can do the final project administration so that they do not bother to go to campus in the final project administration process. The administrative process is starting from the submission of titles, mentoring, exam schedules to the final exam results, both in terms of students and supervisors which are more facilitated with this facility. Hopefully, this system design can be implemented at Indraprasta University PGRI (Unindra) so that it can improve the operational performance of tertiary institutions.
\end{abstract}

Keywords: Aplication system, Final project service, Android

\begin{abstract}
ABSTRAK
Layanan tugas akhir mahasiswa secara online melalui smartphone (android) di Universitas Indraprasta PGRI (Unindra) belum ada, sedangkan jumlah lulusan setiap tahunnya cukup banyak sehingga agak merepotkan staf administrasi dalam melayani mahasiswa yang akan menyusun skripsi. Tujuan penelitian ini adalah untuk memudahkan mahasiswa dalam mengurus administrasi tugas akhir. Metode penelitian yang digunakan adalah Research and Development (R\&D). Hasil yang diharapkan dalam penelitian ini adalah agar mahasiswa yang akan menyusun skripsi lebih mudah dalam proses tugas akhirnya, yaitu dengan mobile phone dapat melakukan administrasi tugas akhir sehingga tidak repot-repot lagi ke kampus dalam proses administrasi tugas akhir. Proses administrasi yaitu dimulai dari pengajuan judul, pembimbingan, jadwal ujian sampai kepada hasil ujian tugas akhir, baik dari sisi mahasiswa maupun dosen pembimbing yang lebih dimudahkan dengan fasilitas ini. Semoga rancangan sistem ini dapat diimplementasikan di Universitas Indraprasta PGRI (Unindra) sehingga dapat menigkatkan kinerja operasional perguruan tinggi.
\end{abstract}

Kata Kunci: sistem aplikasi; layanan tugas akhir; Android 


\section{PENDAHULUAN}

Alat komunikasi saat ini menjadi kebutuhan yang sangat penting karena berupa Smartphone yang dapat digunakan untuk keperluan sehari-hari penggunanya, yaitu sebagai alat komunikasi, media sosial, penyimpanan data, dan lain-lain. Salah satu smartphone yang paling banyak digunakan saat ini adalah smartphone berbasis Android, dimana Android menyediakan platform terbuka bagi para pengembang untuk menciptakan aplikasi mereka sendiri [1].

Sistem aplikasi layanan tugas akhir dirancang untuk menunjang operasional administrasi baik dosen, tenaga kependidikan maupun mahasiswa dalam proses tugas akhir, karena selama ini masih menggunakan cara konvensional yang menyulitkan proses pembimbingan terutaman dalam transportasi di saat ini yang tidak selancar dahulu, walaupun jarak dekat tetapi membutuhkan waktu yang cukup lama. Tujuan dirancangnya sistem aplikasi ini untuk mengatasi hal tersebut dengan menghemat waktu dan tenaga serta biaya dalam operasional pembimbingan tugas akhir. Adapun semua rancangan ini akan dilakukan dengan meng-extract pengetahuan dari Ketua Program Studi (kaprodi) dalam melakukan semua kegiatan yang berkaitan dengan tugas akhir sehingga diharapkan bahwa rancangan ini sesuai dengan apa yang menjadi standar operasional prosedur (sop) yang dilakukan selama ini Penggunaan smartphone berbasis android oleh dosen dan mahasiswa bisa kapan dan di mana saja mereka berada tanpa membuat mereka sulit melakukan tugas-tugas penting seperti pembimbingan ini.

\section{METODE/ PERANCANGAN PENELITIAN PENELITIAN}

Metode penelitian yang digunakan peneliti adalah Research and Development (R\&D), Metode Penelitian dan Pengembangan adalah metode penelitian yang digunakan untuk menghasilkan produk tertentu, dan menguji keefektifan produk tersebut [2].

Metode penelitian dan pengembangan adalah metode penelitian yang digunakan untuk menghasilkan produk tertentu dan untuk menguji efektivitas produk. Untuk menghasilkan produk tertentu, diperlukan penelitian yang menggunakan analisis kebutuhan (menggunakan metode survei atau metode kualitatif), dan untuk menguji efektivitas produk agar produk berfungsi di masyarakat umum, penelitian untuk menguji efektivitas produk (menggunakan metode eksperimental) harus dilakukan [2].

Metode penelitian dasar biasanya digunakan dalam penelitian analisis kebutuhan untuk menghasilkan produk hipotetis. Untuk menguji produk hipotetis, penelitian eksperimental atau tindakan digunakan. Setelah diuji, produk dapat diterapkan. Proses pengujian produk menggunakan eksperimen disebut penelitian terapan. Penelitian dan pengembangan bertujuan untuk menemukan, mengembangkan, dan memvalidasi suatu produk [3].

\section{TINJAUAN PUSTAKA}

Rafael Magalh aes Borges Alexandre Cabral Mota Dalam paper nya mereka mengintegrasikan diagram kelas UML dan OhCircus dengan elemen UML tertulis dalam hal konstruksi OhCircus. Namun, alih-alih pemetaan sintaksis, mereka juga mengusulkan konsep model kelas untuk menangkap asosiasi dan kendala global. Dan pada Akhirnya, integrasi ini untuk membuktikan penyempurnaan asosiasi sebagai atribut, hasil yang menghubungkan analisis dengan desain untuk implementasi dan yang sangat umum di industri [4].

ABD Rahmat, Kudang Boro Seminar, , dan Arif Imam Suroso [5], mereka melakukan penelitian penilaian kondisi penerapan e-learning dan menganalisis faktor-faktor yang memengaruhi keberhasilannya dengan menggunakan model sistem informasi DeLone dan McLean. Data dikumpulkan melalui kuesioner terstruktur dengan mahasiswa dan dosen menjadi responden 
penelitian. Pengumpulan sampel dilakukan dengan metode convenience sampling. Data dari 300 responden kemudian dianalisis dengan Partial Least Square. Hasilnya adalah kualitas informasi, kualitas sistem, dan kualitas layanan berpengaruh positif terhadap kepuasan pengguna. Kualitas layanan dan kualitas informasi berpengaruh positif terhadap penggunaan. Penggunaan berpengaruh positif terhadap kepuasan pengguna, dan penggunaan serta kepuasan pengguna berpengaruh positif terhadap hasil bersih.

Ayu Putri Hanifah, Yuli Fitrisia, dan Dewi Hajar, Merek melakukan penelitian terkait system informasi pelayanan klinik berbasis web, model yang digunakan dalam perancangannya yaitu modelView-Controller (MVC), hasilnya adalah system secara 100\% dapat dibangun untuk evaluasi kepuasan konsumen mencapaiu 0.03, kepuasan dokter 0.13 kepuasan petugas 0.35 , semakin besar nilainnya maka kualifikasinya semakin baik. [6]

Yayan Gustiana, J. H Jaman, Nono Heryana [7], mereka melakukan penetian gterkait pengemabngan system pada perpustakaan dengn metode Dokument Management System (DMS) Model asrsitektur yang digunakan adalah SDLC dengan dibantu Objek Oriented Programing sebagai Tools nya, hasil evaluasi dan kepuasan dari user adalah sebesar $86.80 \%$ hamper semua menyatakan setuju dengan interval antara 50 sampau dengan $100 \%$.

J. H Jaman dan Garno [8], melakukan penelitian dan membuat suatu perancangan system informasi presensi menggunakan sidik jari untuk PNS di Kabupaten Karawang, hasil sistem absensi tersebut direport dan dipantau langsung oleh badan kepegawaian kabupaten karawang dengan nama presensi pegawai kabupaten karawang.

\section{HASIL DAN PEMBAHASAN}

Perancangan sistem aplikasi menggunakan UML, yaitu dengan analisis dan rancangan berorientasi objek. Langkah awal adalah dengan menganalisa kebutuhan pengguna agar sesuai dengan permintaan dan harapan pengguna.

Unified Modelling Language (UML) adalah bahasa yang diusulkan oleh OMG (Object Management Group) untuk sistem pemodelan. Ini menjadi standar de facto karena kemudahan penggunaan dan notasi intuitif. Model UML mewakili deskripsi satu set objek yang mengambil bagian dalam aplikasi dan interaksi yang dikirimkan dari waktu ke waktu [4]

UML memperlihatkan bagaimana pengguna berinteraksi dengan sistem aplikasi.

A. Use Case Diagram.

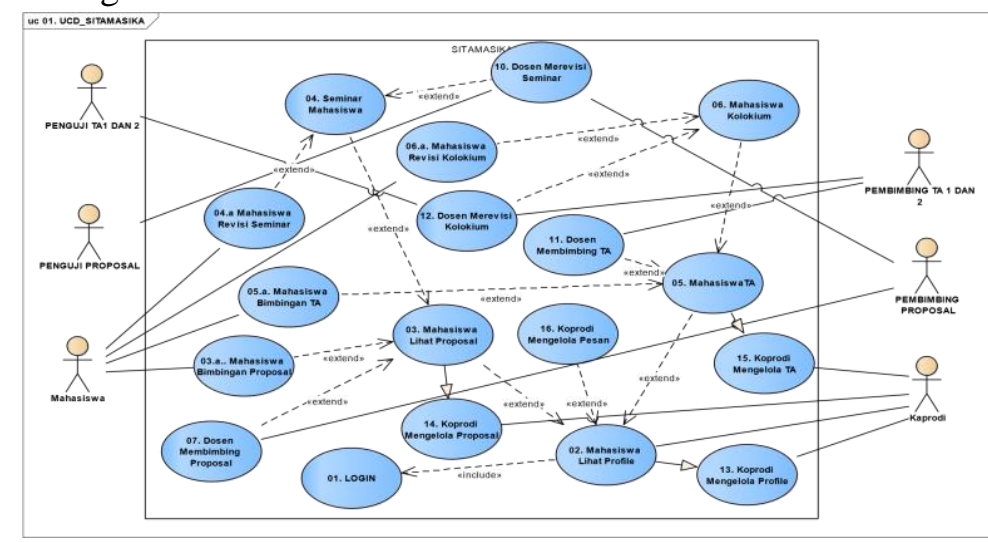

Gambar 1. Use Case Diagram 
Pengguna dan aktor yang terlibat dalam system aplikasi layanan tugas akhir ini, Dosen terbagi lagi menjadi dua aktor yaitu:

1) Kaprodi

Kaprodi dapat melakukan aksi terhadap sisstem sebagai berikut: 1) Melakukan Login sebagai Kaprodi; 2)Mengelola Profile (Dosen dan mahasiswa); 3)Mengelola Proposal dan Tugas Akhir termasuk menetapkan pembimbing dan penguji proposal dan Tugas Akhir.

Dosen melakukan hal-hal yang berkaitan dengan pembimbingan tugas akhir sebagai berikut: (Menginstal sistem aplikasi layanan tugas akhir pada smartphone - Melakukan Login - Melihat Profile - Melihat data mahasiswa bimbingannya - Memmberikan bimbingan Mahasiswa (Proposal dan Tugas Akhir) - Menguji Seminar dan Kolokium Melakukan Penilaian - Memberikan Revisi (Proposal dan Tugas akhir)

2) Mahasiswa

Mahasiswa dapat melakukan hal-hal berkaitan dengan pembimbingan tugas akhir dan berinteraksi dengan sistem aplikasi sebagai berikut: (Melakukan Login - Menjadi Peserta Seminar dan Kolokium - Melihat Profile - Mengajukan Proposal dan Tugas Akhir Melakukan Revisi Proposal dan Tugas Akhir - Melihat Nilai - Melakukan Bimbingan (Proposal dan tugas akhir)

B. Aktifiti Diagram

1) Aktifiti Diagram Profile dan Login

2) Aktifiti Diagram Proposal Mahasiswa

3) Aktifiti Diagram Seminar Mahasiswa

4) Aktifiti Diagram Mahasiswa Bimbingan TA

5) Aktifiti Diagram Kolokium Mahasiswa

6) Aktifiti Diagram Dosen membimbing Proposal

7) Aktifiti Diagram Dosen Seminar

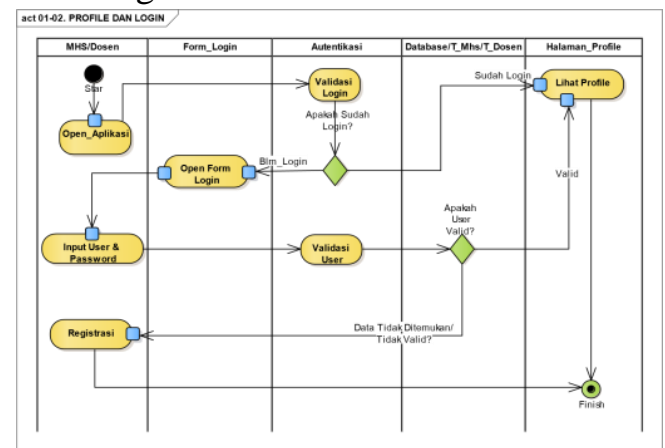

Gambar 2. Aktifiti Diagram Profile dan Login
8) Aktifiti Diagram Dosen membimbing TA

9) Aktifiti Dosen Kolokium

10) Aktifiti Diagram Kaprodi Mengelola Profile

11) Aktifiti Diagram Kaprodi Mengelola Proposal

12) Aktifiti Diagram Kaprodi Mengelola TA

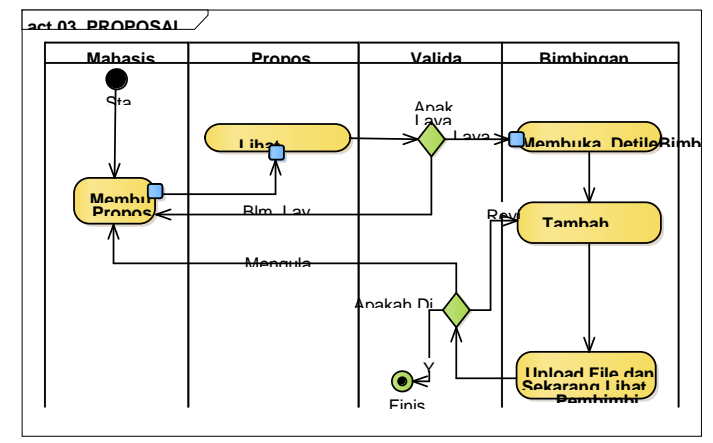

Gambar 3. Aktifiti Diagram Proposal Mahasiswa 
PETIR: Jurnal Pengkajian dan Penerapan Teknik Informatika

Vol. 13, No. 2, September 2020, P-ISSN 1978-9262, E-ISSN 2655-5018

DOI: https://doi.org/10.33322/petir.v13i2.992

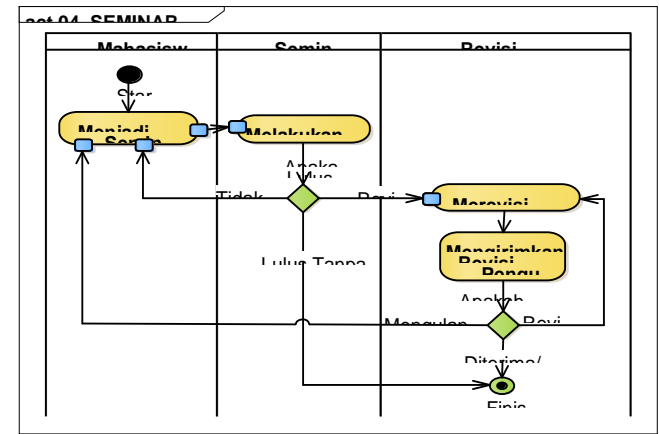

Gambar 4. Aktifiti Diagram Seminar Mahasiswa

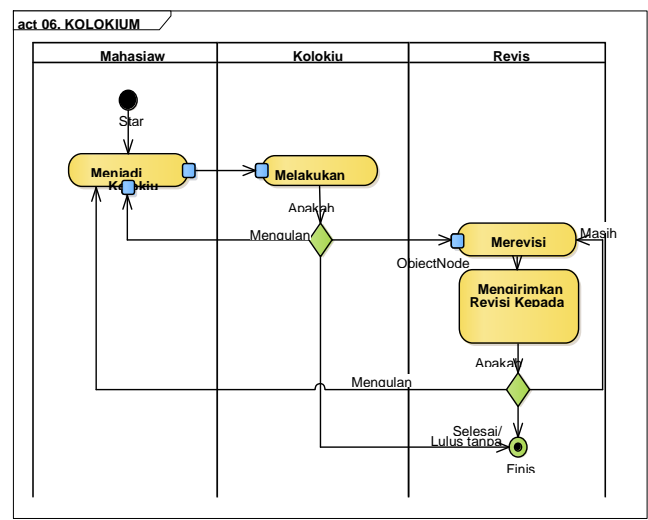

Gambar 6. Aktifiti Diagram Seminar Mahasiswa

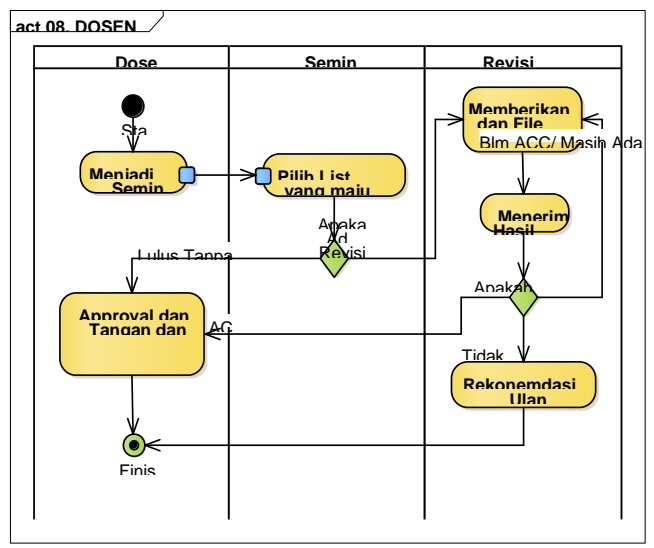

Gambar 8. Aktifiti Diagram Dosen Seminar

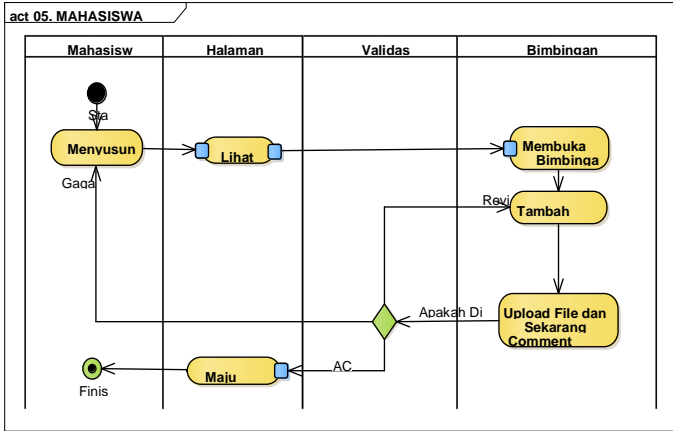

Gambar 5. Aktifiti Diagram Seminar Mahasiswa

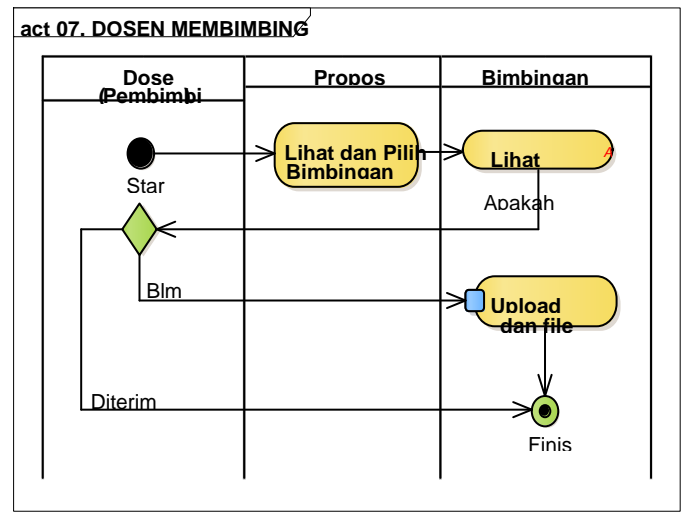

Gambar 7. Aktifiti Diagram Dosen Membimbing Proposal

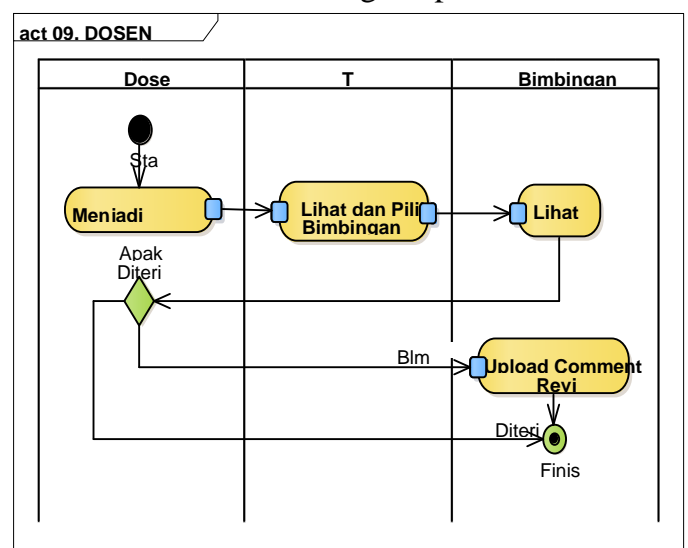

Gambar 9. Aktifiti Diagram Dosen Membimbing TA 


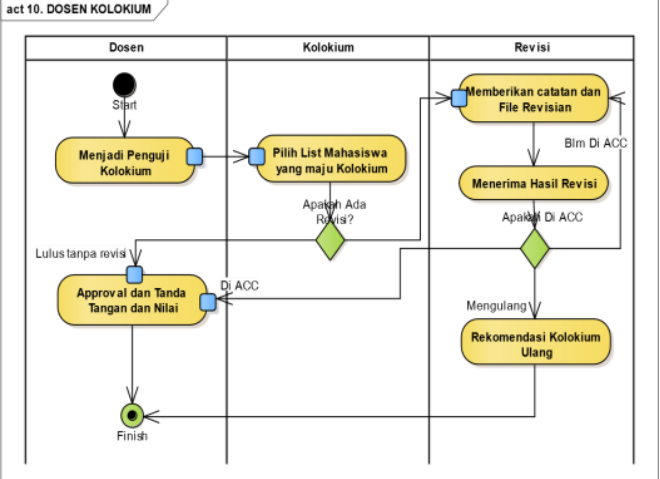

Gambar 10. Aktifiti Diagram Dosen Kolokium

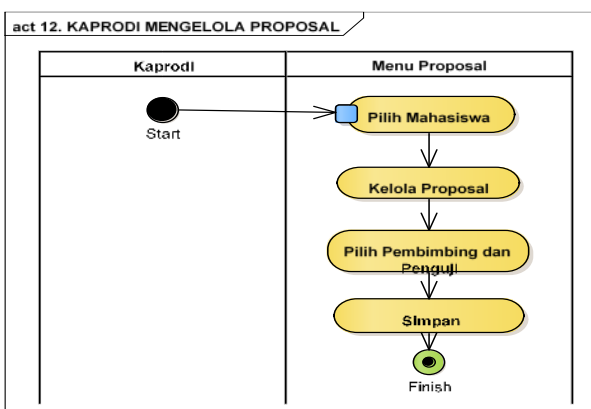

Gambar 12. Aktifiti Diagram Kaprodi Mengelola Proposal

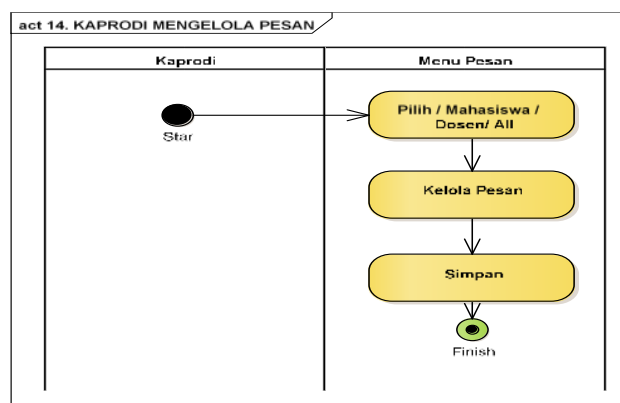

Gambar 14. Aktifiti Diagram Kaprodi Mengelola Pesan

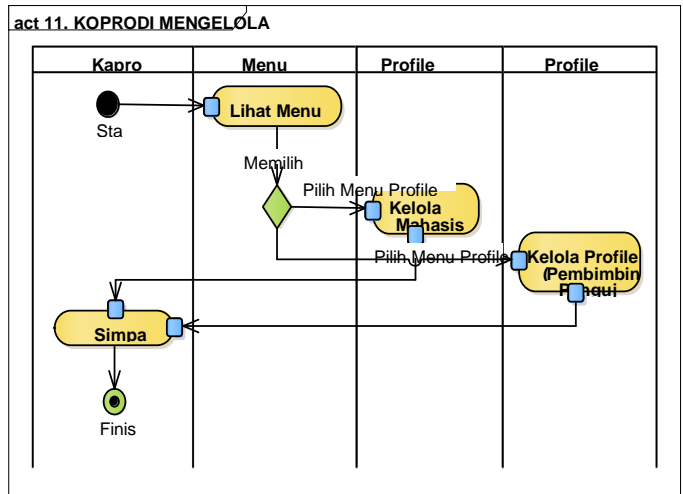

Gambar 11. Aktifiti Diagram Kaprodi mngelola profile

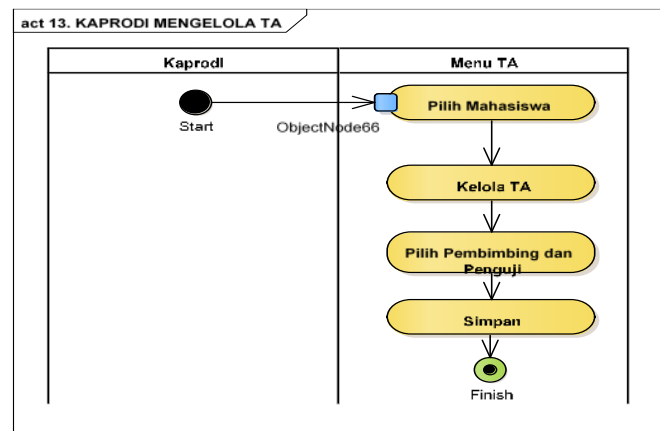

Gambar 13. Aktifiti Diagram Kaprodi Mengelola Tugas Akhir 
C. Class Diagram

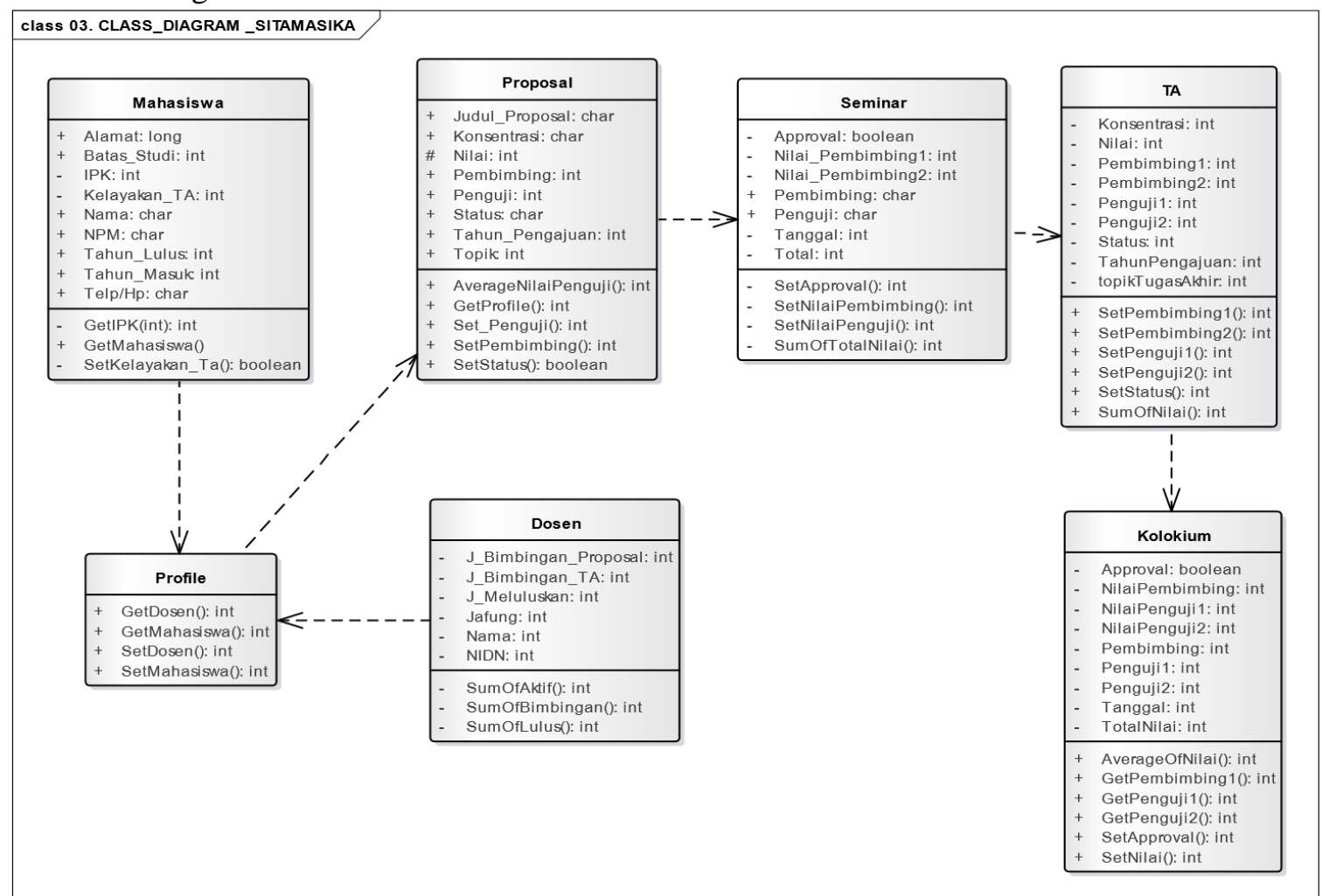

Gambar 15. Class Diagram Sistem Tugas Akhir

Selanjutnya menentukan Class untuk menggambarkan objek atribut, properti, dan hubungan umum antara objek dan semantik. Pada diagram ini menggambarkan seluruh class yang ada didalam sistem termasuk hubungannya.

\section{MockUp}

Untuk melengkapi rancangan dari system yang akan dibangun disini diperlukan suatu interface agar user dapat mengerti dan memahami terkait dari fungsi-fungsi aplikasi yang akan di tawarkan berikut Mockup yang telah di bangun.

1) Mockup Login dan profile

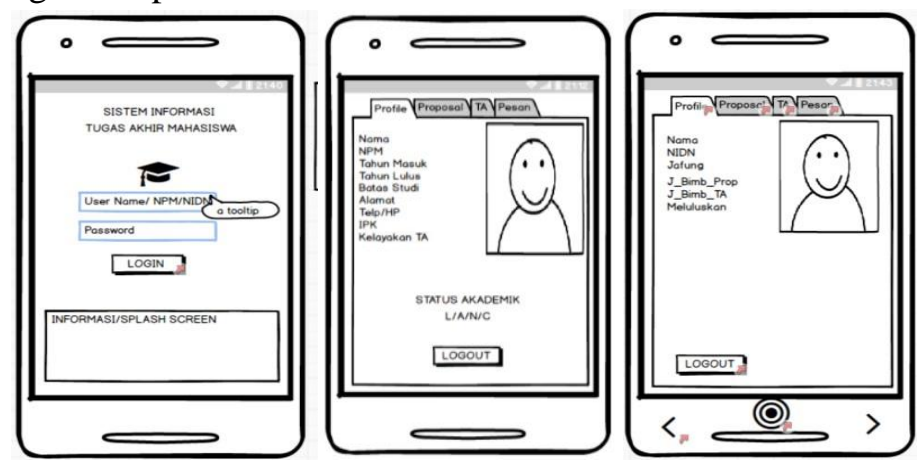

Gambar 16. Tampilan Aplikasi Login dan Profile dengan View Mahasiswa dan Dosen 
2) Mockup Halaman Proses Pengajuan Proposal
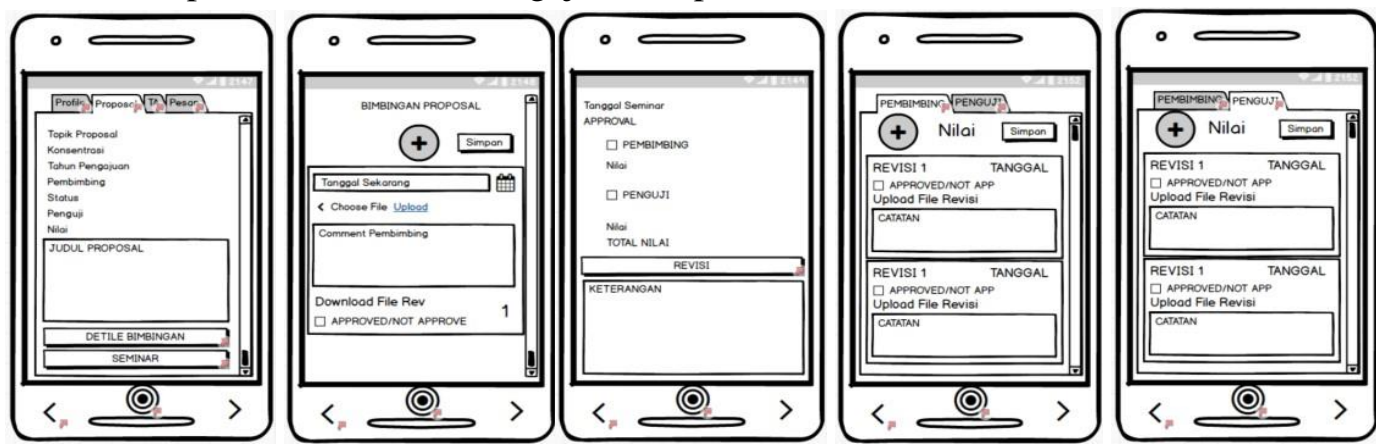

Gambar 17. Tampilan Aplikasi Halaman Proposal, Bimbingan, Seminar dan Revisi Seminar View Mahasiswa

3) Mockup Halaman Tugas Akhir, Bimbingan dan dan Proses Kolokium

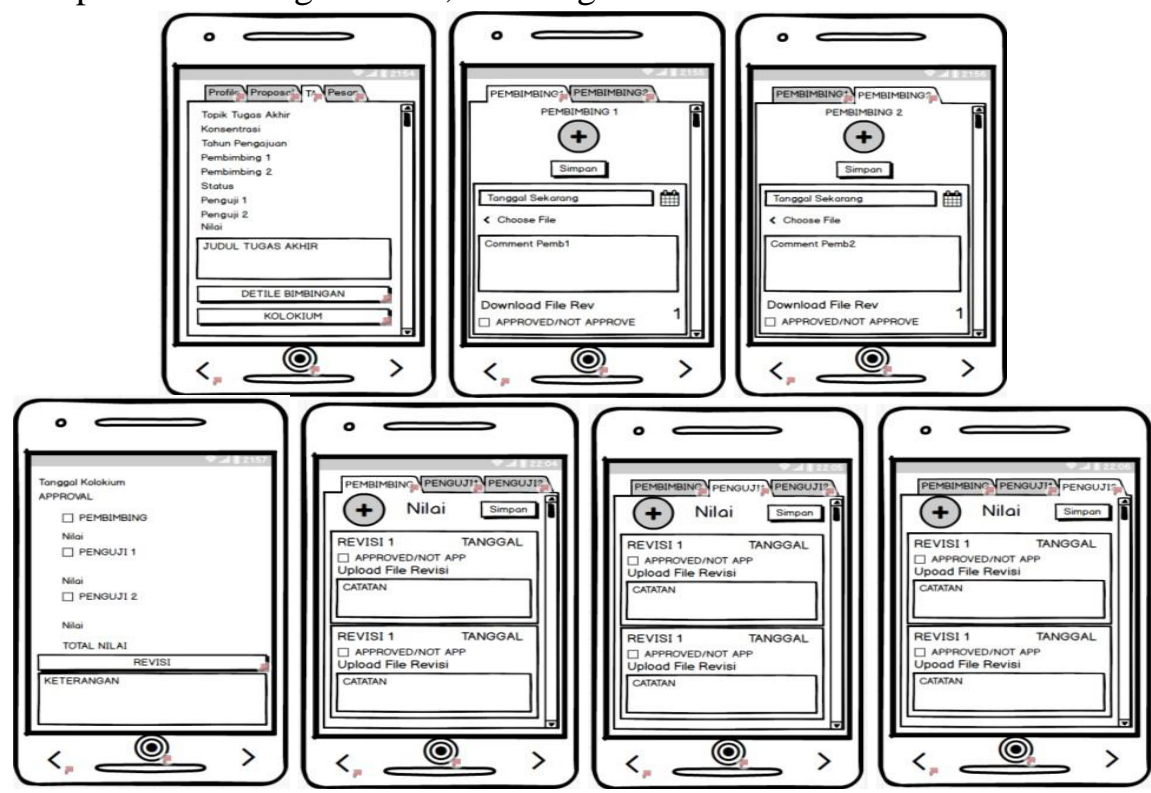

Gambar 18. Tampilan Aplikasi Halaman Tugas Akhir, Bimbingan dan Proses Kolokium View Mahasiswa

4) Mockup Halaman Proposal dan Proses Seminar pada Tampilan Dosen
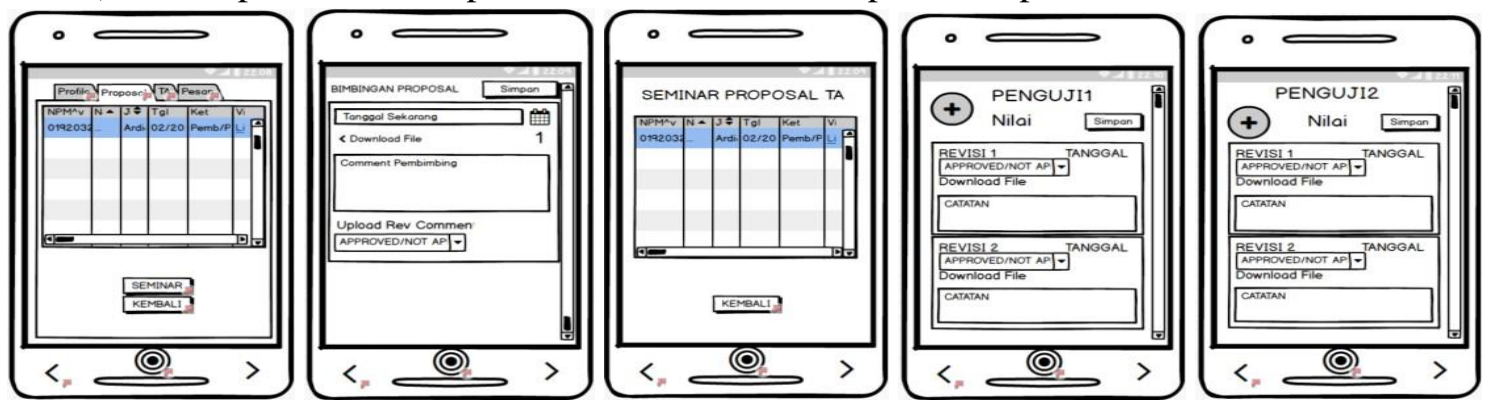

Gambar 19. Tampilan Aplikasi Halaman Proposal dan Proses Seminar View Dosen 
PETIR: Jurnal Pengkajian dan Penerapan Teknik Informatika

Vol. 13, No. 2, September 2020, P-ISSN 1978-9262, E-ISSN 2655-5018

DOI: https://doi.org/10.33322/petir.v13i2.992

5) Mockup Halaman Tugas Akhir dan Revisi Tugas Akhir

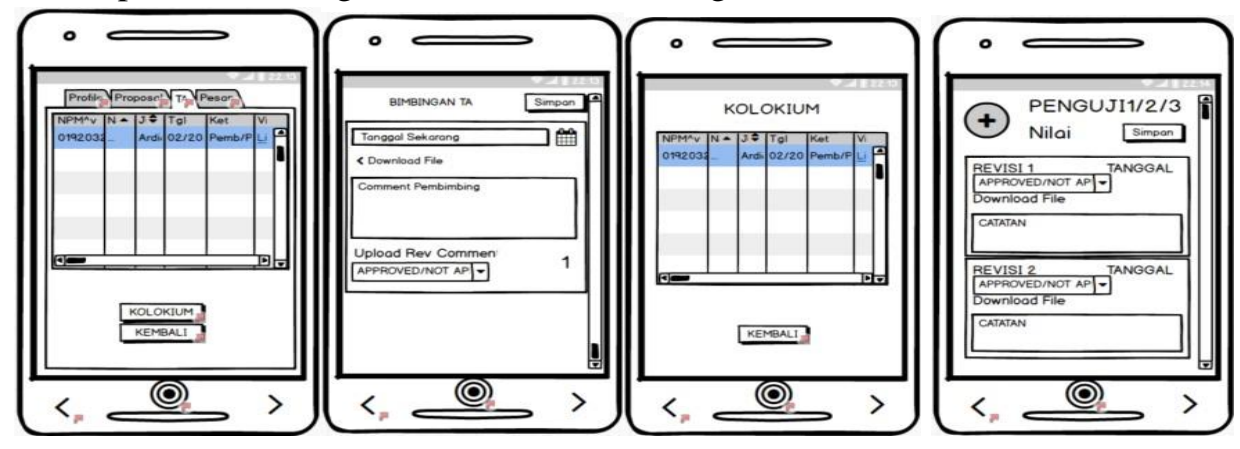

Gambar 20. Tampilan Aplikasi Halaman Tugas Akhir dan Proses Kolokium View Dosen

6) Mockup Halaman Pesan

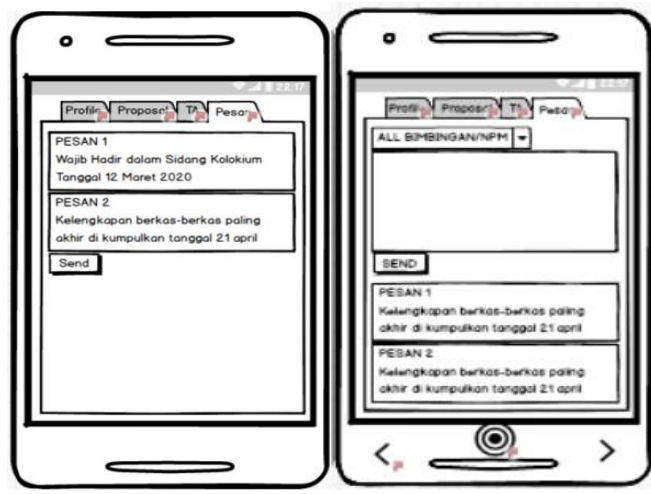

Gambar 21. Tampilan Aplikasi Halaman Pesan View Dosen dan Mahasiswa

7) MockUp Kelola Profile Mahasiswa dan Dosen

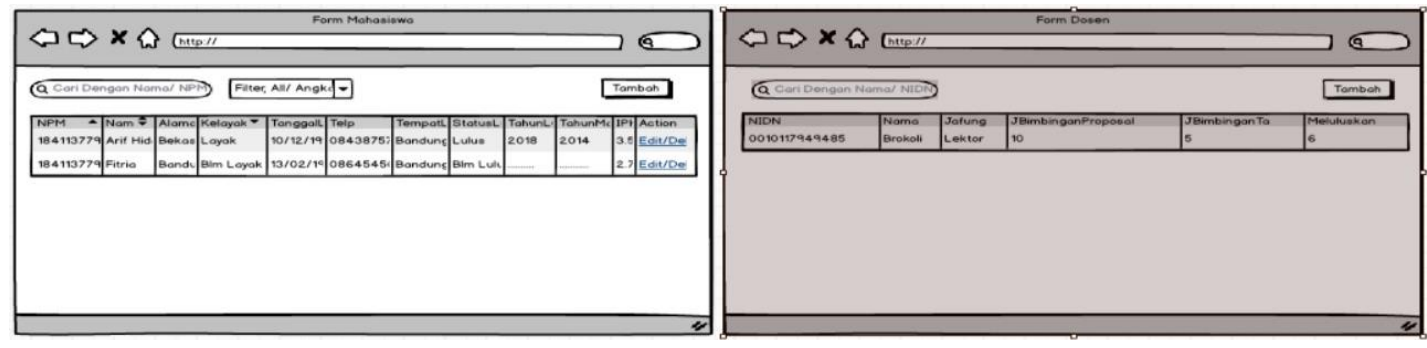

Gambar 22. Tampilan Aplikasi Halaman Kelola Profile Mahasiswa dan Dosen

8) MockUp Kelola Proposal dan Tugas Akhir

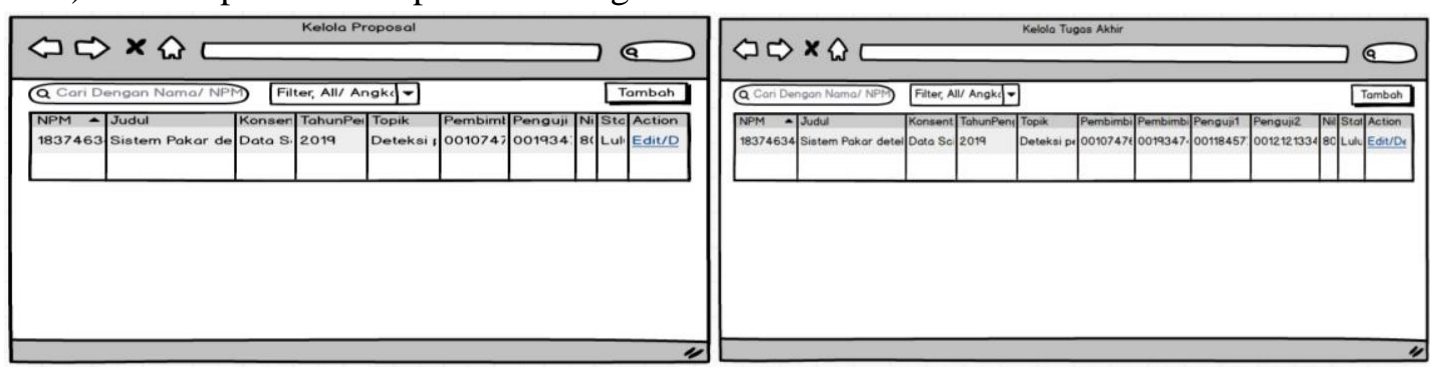

Gambar 23. Tampilan Aplikasi Halaman Kelola Proposal dan Tugas Akhir 
9) MockUp Kelola Pesan

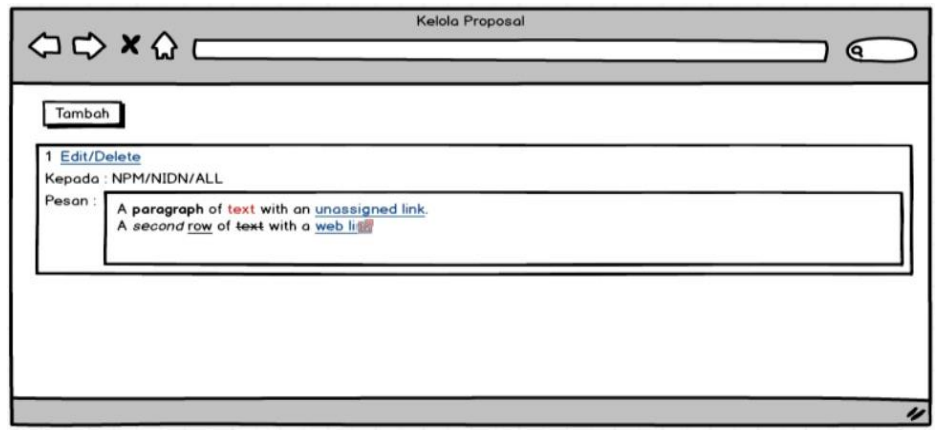

Gambar 24. Tampilan Aplikasi Halaman Pesan View Kaprodi

\section{GAP ANALISIS}

Dari hasil studi banding dengan beberapa kampus di jawabarat, ada beberapa persamaan terkait aplikasi yang dibangun diantarannya adalah 1) Bisa melakukan bimbingan tehradap makasiswa, 2) dapat melakukan komuniksi du arah, 3) dapat melakukan upload dan download dokumen, 4) dapat melakukan persetujuan bimbingan dan pengujian, dilain fitur banyak juga perbedaan yang menjadi ciri khas dari penelitian ini yaitu 1) aplikasi yang di bangun menggunkanan konsep Knowledge manajemen system yang pada hakikatnnya adalah untuk melakukan extraksi pengetahuan dari kaprodi dalam melakukan dan mengelola tugas akhir mahasiswa sehingga dalam hal ini aplikasi yang di bangun adalah unik karena di sesuai dengan sop dan realisai keadaan user, 2) Aplikasi tersebut berbasis android dengan menggunakan mockup sebagai bagian dari perancangannya.

\section{KESIMPULAN}

Peralihan sistem konvensional kepada sistem berbasis Android memberikan respon yang cukup tinggi. Pengembangan sistem aplikasi menggunakan UML dan perancangan aplikasi lebih mudah karena sudah berbasis objek. Perancangan ini diharapkan dapat membantu meringankan dosen dan mahasiswa dalam pembimbingan tugas akhir sehingga lebih optimal dalam pengolahan data melalu smartphone yang dapat memfasilitasi dosen dan mahasiswa dalam melakukan transaksi, adapun hasil evaluasi terhadap system dilakukan dengan pengguna, yang mana hasilnnya adalah sesuai dengan harapan pengguna tersebut.

Pengembangan lebih lanjut diperlukan dan harapannya adalah demi penyempurnaan sistem aplikasi layanan tugas akhir ini

\section{DAFTAR PUSTAKA}

[1] A. Pratomo, Media Interaktif Berbasis Android Banjarmasin, Banjarmasin: Poliban Press, 2019.

[2] Sugiyono, Metode Penelitian Pendidikan Pendekatan kuantitatif, Kualitatif, dan R \& D, Bandung: Alfabeta, 2009.

[3] W. R. Brog and M. D. Gall, Educational Research: An Introduction, New York: Longman, 1983.

[4] R. M. Borges and A. C. Mota, "Integrating UML and Formal Methods," Electronic Notes in Theoretical Computer Science, vol. 97, no. 122, p. 184, 2007. 
[5] A. Rahmat, K. B. Seminar and a. I. Suroso, "Evaluasi Keberhasilan E-Learning Dalam Perspektif Sistem Informasi," Jurnal Aplikasi Manajemen dan Bisnis, Vol. 5 No. 3, September 2019, vol. 5, no. 3, pp. 373-384, 2019.

[6] A. P. Hanifah, Y. Fitrisia and D. hajar, "Sistem Informasi Pelayanan Klinik Berbasis Web," Rekayasa Sistem dan Teknologi Informasi, vol. 2, no. 3, pp. 668-673, 2018.

[7] Y. Gustiana, J. H. Jaman and N. Heryanan, "Rancang Bangun Perpustakaan Digital Berbasis Document Management System pada Fakultas Ilmu Komputer UNSIKA," Jurnal Informatika: Jurnal Pengembangan IT (JPIT), vol. 3, no. 2, pp. 225-232, 2018.

[8] J. H. Jaman and Garno, "Perancangan Sistem Informasi Presensi Menggunakan Sidik Jari Untuk Pegawai Negeri Kabupaten Karawang," TechnoExplore, vol. 2, no. 1, pp. 32-38, 2017.

[9] A. Gunasekaran, H. B. Marri, R. E. McGaughey and M. D. Nebhwani, "E-commerce and its impact on operations management," International Journal of Production Economics, vol. 75, no. 1-2, pp. 185-197, 2002.

[10] T. K. Kundu and K. Paul, "Android on Mobile Device An Energy Prespective," in IEEE International Conference on Computer and Information Technology, Bradford, 2010. 